\title{
Fragrances as new contaminants in the Venice lagoon
}

\author{
Marco Vecchiato ${ }^{\mathrm{a}, *}$, Simone Cremonese ${ }^{\mathrm{a}}$, Elena Gregoris ${ }^{\mathrm{b}}$, Elena Barbaro ${ }^{\mathrm{a}}$, \\ Andrea Gambaro ${ }^{\mathrm{a}, \mathrm{b}}$, Carlo Barbante ${ }^{\mathrm{a}, \mathrm{b}}$ \\ a Department of Environmental Sciences, Informatics and Statistics (DAIS), Ca' Foscari University of Venice, Via Torino 155, 30172, Venezia-Mestre, Venice, Italy \\ b Institute for the Dynamics of Environmental Processes (IDPA-CNR), Via Torino 155, 30172, Venezia-Mestre, Venice, Italy
}

\section{H I G H L I G H T S}

- Fragrance Materials (FMs) were quantified in the surface waters of the Venice lagoon.

- First detection in environmental samples of most of the selected FMs.

- Salicylates resulted in general the most abundant and widespread compounds.

- FMs are persistently emitted in the environment.

- Emitting sources and tidal dilution resulted key factors.

\section{A R T I C L E I N F O}

\section{Article history:}

Received 24 March 2016

Received in revised form 27 May 2016

Accepted 27 May 2016

Available online 4 June 2016

\section{Keywords:}

Fragrance materials (FMs)

Personal care products (PCPs)

Water

Venice
GR A P H I C A L A B S T R A C T



\section{A B S T R A C T}

Fragrance Materials (FMs) are omnipresent components of household and Personal Care Products (PCPs). In spite of their widespread use, little is known about their environmental occurrence. We selected 17 among the longest-lasting and most stable fragrance ingredients that are commercially available, namely: Amberketal, Ambrofix, Amyl Salicylate, Benzyl Salicylate, Bourgeonal, Dupical, Hexyl Salicylate, Isobutavan, Lemonile, Mefranal, Myraldene, Okoumal, Oranger Crystals, Pelargene, Peonile, Tridecene-2-Nitrile, Ultravanil. A new analytical method was developed to quantify FMs in water samples and it was applied to perform the first study about the distribution of these compounds in the surface waters of the city of Venice and its lagoon. Total FMs concentrations range from about $30 \mathrm{ng} \mathrm{L}^{-1}$ to more than $10 \mu \mathrm{g} \mathrm{L}-1$ in polluted canals during the low tide. Sewage discharges were supposed to be the main sources of the selected FMs in the environment. Salicylates, oestrogenic and allergenic compounds, were in general the most abundant and widespread components. This study reports for the first time the detection of most of the selected FMs in surface waters and represent the first step to understand their environmental fate.

(c) 2016 Elsevier B.V. All rights reserved.

\footnotetext{
* Corresponding author.

E-mail address: vecchiato@unive.it (M. Vecchiato).
}

\section{Introduction}

Perfumes are ubiquitous in daily life. The majority of cosmetics, toiletries, and a variety of household and Personal Care Products (PCPs) contain Fragrance Materials (FMs). In spite of their widespread use, little is known on the environmental fate of these compounds. Every day, 
humans are adsorbing an unknown number of substances by direct application of PCPs (Zhang et al., 2013). Pharmaceuticals and PCPs have been recognized as contaminants of emerging concern. Previously undetected chemicals are being discovered in water, and can represent a risk for wildlife and human health (Daughton and Ternes, 1999). Compounds of particular concern are those used in large volumes, persisting in the environment and bioaccumulative (Peck, 2006). The study of these emerging pollutants is one of the main open scientific questions in environmental and analytical chemistry and it is fundamental to understand their environmental risk. The case of the synthetic musks is emblematic of the environmental concerns linked to the usage and discharge of FMs, originating a wide scientific debate (Daughton and Ternes, 1999; Peck, 2006).

The aim of this work is to evaluate the occurrence and distribution of FMs in the environment. We chose 17 among the longest-lasting and most stable fragrance ingredients that are commercially available to assess their potential accumulation in the ecosystem (Table SI1). More precisely, the trade names (Givaudan ${ }^{\circledR}$ ) of the selected FMs are: Amberketal, Ambrofix, Amyl Salicylate, Benzyl Salicylate, Bourgeonal, Dupical, Hexyl Salicylate, Isobutavan, Lemonile, Mefranal, Myraldene, Okoumal, Oranger Crystals, Pelargene, Peonile, Tridecene-2-Nitrile, Ultravanil. These FMs have a wide range of possible uses in commercial products which present very different and aggressive characteristics, such as liquid bleach and acid cleaners (eindex.givaudan.com). The selected FMs have a molecular weight ranging between 152 and 288 and their persistence as fragrances (tenacity on blotter) ranges from a few weeks to months. Their chemical stability and persistence as fragrances are indications of their possible persistence in the environment. In order to understand the risk in using and discharging these substances, the key issue is to study their environmental fate and distribution in environmental compartments. Once released into the water, sufficiently persistent FMs can evaporate into the atmosphere, sink in the sediment and finally even accumulate in biota. The octanol-water repartition constants of the 17 selected FMs range from 2.0 to more than 6.0 (Table SI1) and are comparable to those of bioaccumulating pollutants such as PAHs and PCBs (Jonker and Koelmans, 2002). However, at present the hypothesis of the bioaccumulation of the 17 FMs is still far from proven.

To the best of our knowledge, there are no data available in the literature about the environmental occurrence of most FMs. Benzyl Salicylate is the only FM among the ones selected whose environmental occurrence has been discussed in literature. Because of the very low prices of these products (under $\$ 5 / \mathrm{kg}$ ), the consumption of Benzyl, Hexyl and Amyl Salicylates has grown rapidly over the last years, reaching an estimated worldwide annual consumption of respectively 8500,7000 and 6800 metric tons in 2010 (Gaudin, 2014). The estimated total human skin exposure of Benzyl Salicylate from the use of multiple cosmetic products is $0.4 \mathrm{mg} \mathrm{kg}^{-1}$ day $^{-1}$ (Lapczynski et al., 2007). This compound, used among other purposes as sun-blocking agent due to UV-filter properties (Kameda et al., 2011), is included in the EU list of allergenic fragrances (Heisterberg et al., 2011), and it was recently found to have an oestrogenic activity comparable to bisphenol A (BPA) (Zhang et al., 2012). Other authors found that Benzyl Salicylate gives oestrogenic responses in human breast cancer cells, potentially promoting the development of this disease (Charles and Darbre, 2009). The concentrations of Benzyl and Hexyl Salicylates were measured in U.S. and European wastewater treatment plants (WWTPs) (Simonich et al., 2002, 2000), where were reported almost quantitative removals (98.7\%) of these substances after secondary treatment. Benzyl Salicylate was detected in other WWTPs in Spain (Godayol et al., 2015; Negreira et al., 2010) and Japan (Kameda et al., 2011), reporting similar removals. Data about its occurrence in river waters are even fewer (Kameda et al., 2011; Negreira et al., 2010; Vila et al., 2016), while in Japanese seawater samples it was investigated but not detected (Tashiro and Kameda, 2013). Given its large use as a fragrance, Benzyl Salicylate was detected also in indoor air (Lamas et al., 2010). A review of the toxicological and dermatologic effects of Benzyl Salicylate, along with other
FMs, was published by the Research Institute for Fragrance Materials (RIFM) (Lapczynski et al., 2007).

The first step to assess the environmental fate of these FMs is to understand their emission patterns, identifying which of the selected fragrances are emitted in greater amount and their concentration levels in the environment. This is the main objective of this pilot study. As in the case of other PCPs (Daughton and Ternes, 1999), we hypothesized that the main route of entry in the environment of the selected FMs is through wastewaters. In this paper we will focus on the occurrence of FMs in the surface waters of the city of Venice and its lagoon, since it is likely the first environmental compartment to carry their load. As the medieval historical center is almost completely lacking a sewerage system, FMs are discharged directly into the canals. The historical center of Venice has a population of about 56,000 inhabitants, to which we should add a similar number of commuters and the tourists spending 7 million nights per year in the island. The Venice Lagoon is a basin with an area of $549 \mathrm{~km}^{2}$ and an average depth of about $1.2 \mathrm{~m}$. Three inlets connect it to the Adriatic Sea, enabling an average exchange of over $50 \%$ of the water volume of the lagoon in $12 \mathrm{~h}$, depending on the tidal excursion (Gambaro et al., 2009). The island of Burano is set in the northern lagoon with a population of about 2700 inhabitants and its sewerage system was only partially implemented in the last years. Although Venice and the lagoon became an UNESCO world heritage site in 1987, these areas are heavily affected by anthropogenic activities such as industrial emissions from Porto Marghera, traffic pollution from the nearby Mestre motorway, touristic and merchant ship traffic, airport emissions and domestic heating (Gregoris et al., 2014). The direct connection between urban emissions and the natural environment makes the Venice lagoon a perfect macrocosm laboratory to carry out the first pilot study about the distribution of the 17 FMs.

\section{Materials and methods}

\subsection{Samplings}

Three sampling campaigns were performed in order to validate the analytical method and characterize the distribution and emission patterns of the selected fragrances in the surface water system. Samples were collected in solvent-rinsed glass bottles in the sites shown in Fig. 1. In the first campaign (S1; 2015-04-16) we collected four exploratory samples in the sites Ve1-Ve4. The second campaign (S2) was the most extensive one and aimed to determine the spatial distribution of the analytes: 14 samples were collected on the island of Venice (Ve1-Ve14), 2 in the open lagoon (La1 and La2) and 6 on the island of Burano (Bu1-Bu6). Samplings were performed during the tidal quadrature (2015-10-05/06 Fig. SI1), when the movements of the water masses are minimized, thereby obtaining samples that were representative of the local emissions and in steady and comparable conditions across the different sites. The third campaign aimed instead to study the temporal evolution and the influence of the tides: samples were collected during high, medium and low tides at the sites Ve1, Ve2 and Bu2 during the highest excursions of the astronomical tide (2015-12-10/11/12) for a total of 15 samples.

\subsection{Sample processing}

Water samples ( $500 \mathrm{~mL}$ ) were spiked with internal standard and extracted using $200 \mathrm{mg}$ Oasis ${ }^{\circledR}$ HLB cartridges (Waters Corp., Milford, MA USA) previously conditioned with $10 \mathrm{~mL}$ of dichloromethane followed by $10 \mathrm{~mL}$ of ultrapure water (ELGA, High Wycombe, UK). Quantification was performed using Phenanthrene ${ }^{13} \mathrm{C}$ as internal standard (CLM2451, Cambridge Isotope Laboratories Inc., Andover, MA USA), adding to the samples $50 \mu \mathrm{L}$ at the concentration of $1 \mathrm{ng} \mu \mathrm{L}^{-1}$ prior to the extraction. Pesticide-grade dichloromethane, toluene and acetone (Romil Ltd., Cambridge, Great Britain) were used. Extraction was performed under vacuum approximately at the rate of $10 \mathrm{~mL} \mathrm{~min}^{-1}$, followed by elution under gravity of $1 \mathrm{~mL}$ of toluene and $15 \mathrm{~mL}$ of dichloromethane. 


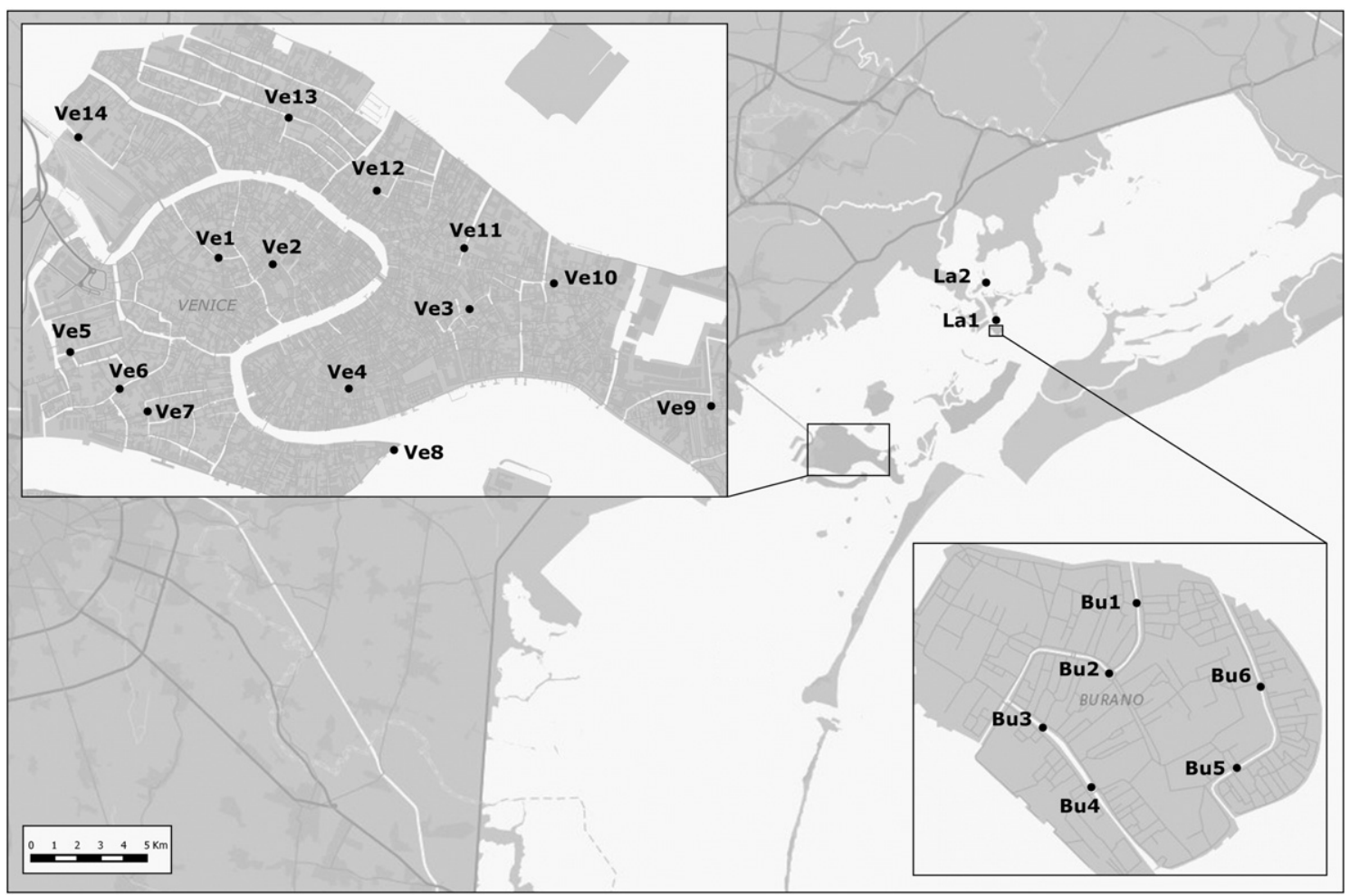

Fig. 1. Sampling sites in Venice (Ve1-14), Burano (Bu1-6) and open lagoon (La1-2).

On the basis of literature and existing methods (Argiriadis et al., 2014; Keil and Neibauer, 2009; Peck, 2006; Simonich et al., 2000; Vecchiato et al., 2015), different solvents and aliquots were tested for the elution of the FMs from the SPE cartridges and the final procedure derives from the combination of the most effective ones. Cartridges were not dried under vacuum in order to prevent possible losses of the more volatile analytes. Eluates were dried with an aliquot of $\mathrm{Na}_{2} \mathrm{SO}_{4}$ and transferred into Zymark tubes together with $5 \mathrm{~mL}$ of dichloromethane rinse of the $\mathrm{Na}_{2} \mathrm{SO}_{4}$. Samples were reduced to $250 \mu \mathrm{L}$ under a gentle nitrogen flow at $23^{\circ} \mathrm{C}$ (Turbovap II ${ }^{\circledR}$, Caliper Life Science, Hopkinton, MA, USA) and transferred into vials.

\subsection{Analysis}

The instrumental analysis was conducted by HRGC-LRMS (7890A5975C, Agilent Technologies) on a 60-m HP-5MS column $(0.25 \mathrm{~mm}$ I.D., $0.25 \mu \mathrm{m}$; Agilent Technologies, Avondale, USA). Operating conditions of the GC were optimized as follows: injection $2 \mu \mathrm{L}$ splitless mode; purge flow $50 \mathrm{~mL} \mathrm{~min}{ }^{-1}$ after $1.5 \mathrm{~min}$; injector temperature $280{ }^{\circ} \mathrm{C}$; transfer line temperature $290{ }^{\circ} \mathrm{C}$; oven temperature program: $90{ }^{\circ} \mathrm{C}(2 \mathrm{~min}), 3^{\circ} \mathrm{C} \mathrm{min}^{-1}$ to $150{ }^{\circ} \mathrm{C}(3 \mathrm{~min}), 3{ }^{\circ} \mathrm{C} \mathrm{min}^{-1}$ to $180{ }^{\circ} \mathrm{C}$ (5 min), $20^{\circ} \mathrm{C} \min ^{-1}$ to $280^{\circ} \mathrm{C}(1 \mathrm{~min})$, post run $305^{\circ} \mathrm{C}(15 \mathrm{~min})$; carrier gas (helium) at $1.2 \mathrm{~mL} \mathrm{~min}^{-1}$. Analyses were performed in SIM mode monitoring two ions for quantification and confirmation purposes: quantifier and qualifier ions are reported in Table SI2. Crude concentrations were corrected using the instrumental response factors and results are mean-blank corrected. Since most of 17 FMs (Amberketal, Bourgeonal, Dupical, Lemonile, Mefranal, Myraldene, Okoumal, Pelargene, Peonile, Tridecene-2-Nitrile) are not available at analytical or reagent grade, all the following results are expressed as concentration of the commercial product.

\subsection{Method verification}

A working mixture solution of the FMs was prepared in dichloromethane starting from the single pure commercial products. Recovery tests were performed adding known amounts of the working solution to $500 \mathrm{~mL}$ of ultrapure water and by carrying out the procedure described above. The mean extraction recoveries of the different FMs are in general above $80 \%$ (Table SI3). Trueness tests using Phenanthrene ${ }^{13} \mathrm{C}$ as internal standard showed differences with the true spiked values below $10 \%$ for most of the FMs. Other isotope-labelled compounds were tested as internal standard: Acenaphthylene ${ }^{13} \mathrm{C}$, Benzo(a)Pyrene ${ }^{13} \mathrm{C}$ (CLM-2477, CLM-2722 CIL) and Vanillin ${ }^{13} \mathrm{C}$ (Sigma-Aldrich). The latter two were unsatisfactory in terms of trueness, while Acenaphthylene exhibited performances comparable but slightly lower than Phenanthrene (Table SI4). The Instrumental Detection Limits (IDL) were obtained considering a signal-to-noise ratio greater than 3 . Procedural blanks were conducted extracting ultrapure water (ELGA) with the same procedure described above. The Method Detection Limit (MLD) was calculated as three times the standard deviation of the blank signal (Table SI5). The role of the particulate was tested comparing filtered and unfiltered previous water samples (Table SI6): results of the unfiltered total samples were consistent with the sum of the filtered and particulate fractions. Re-extractions of the preliminary samples and re-elutions of the SPEs gave results similar to blanks, and the final procedure was therefore deemed suitable for analyzing FMs in surface water samples. Other samplings (S4 - Table SI7) were performed at the site Ve1 to assess the short-term evolution of the system: variability was in general less than $10 \%$, giving an indication about the validity of the results obtained in the other campaigns.

\section{Results and discussion}

\subsection{Distribution of FMs}

Preliminary samples (Ve1-4S1) confirmed the applicability of the analytical method and the results were later confirmed in the second campaign (Table SI8). Ve1S1 showed high concentrations of total FMs (490 $\mathrm{ng} \mathrm{\textrm {L } ^ { - 1 }}$ ) while in Ve3S1 levels were significantly lower (62 $\mathrm{ng} \mathrm{L}^{-1}$ ). In the campaign S2 (Fig. 2 - Table SI8) higher concentrations were found in the innermost canals, both in Venice and Burano. 

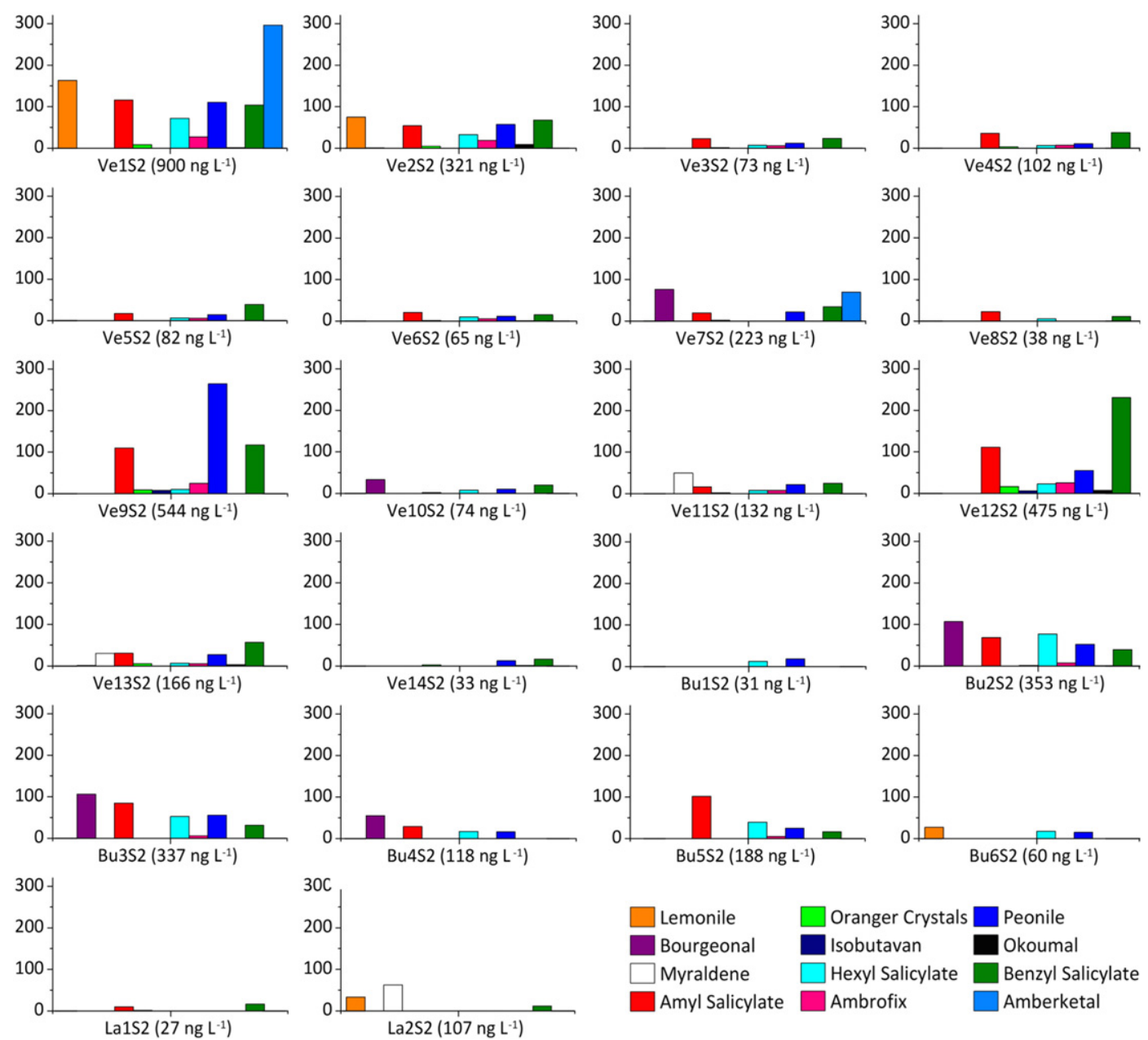

Fig. 2. Results of the campaign S2. Total FMs are reported near each sample.

The station Ve1 was found again to be the most polluted one (900 $\mathrm{ng} \mathrm{L}^{-1}$ ). Relatively high concentrations in Venice were detected also in Ve9S2 (544 $\left.\mathrm{n} \mathrm{L}^{-1}\right)$ and Ve12S2 (475 $\left.\mathrm{ng} \mathrm{L}^{-1}\right)$, all collected in residential areas. Samples Ve3S2, Ve6S2 and Ve10S2, though collected in comparable canals, were lower of about one order of magnitude, being respectively at $73 \mathrm{ng} \mathrm{L}^{-1}, 65 \mathrm{ng} \mathrm{L}^{-1}$ and $74 \mathrm{ng} \mathrm{L}^{-1}$. This is likely due to differences in specific emissions and water circulation: each sample should therefore be regarded as representative of its local site, rather than an extended area. Samples from Ve1, Ve2 and Ve3 showed an increase if compared to the first sampling, while Ve4S2 decreased. Notably concentrations remained in the same order of magnitude even in different seasons (April vs. October). As in Venice, in Burano the highest levels were detected in the inner part of the island, namely Bu2S2 (353 ng L $\mathrm{L}^{-1}$ ) and Bu3S2 (337 ng L ${ }^{-1}$ ). The outer samples, Bu1S2 (31 ng L ${ }^{-1}$ ) and Bu6S2 (60 ng L ${ }^{-1}$ ) were similar to the lower ones in Venice. The concentrations in the lagoon samples are comparable to the lowest ones found in the urban sites (Table SI8), confirming the dilution effect linked to water circulation. Salicylates were in general the most abundant and widespread compounds, with the sum of Amyl, Hexyl and Benzyl Salicylate constituting more than $50 \%$ of the total concentration in $60 \%$ of the samples. Other major FMs were Oranger crystals, Ambrofix and Peonile, which were detected in most of the samples, while Lemonile, Bourgeonal, Myraldene, Isobutavan, Okoumal and Amberketal were found less frequently. Ultravanil, Pelargene, Mefranal, Tridecene-2-Nitrile and Dupical were always below MDL in the campaigns $\mathrm{S} 1$ and $\mathrm{S} 2$

\subsection{Tidal dynamics}

The third sampling campaign (S3) highlighted how FMs in the urban canals become more concentrated during the low tide (Fig. 3 ). This trend is clearly visible in Venice in both Ve1 and Ve2 and on both sampling days. Total FMs start from around $500 \mathrm{ng} \mathrm{L}^{-1}$ during the high tide, rising by more than one order of magnitude after $6 \mathrm{~h}$ (Table SI9). Such a behavior is consistent with a roughly steady emission of FMs throughout the day. Remarkably, on the second day, concentrations were higher than on the previous one in both stations, despite similar tidal excursions. In Burano total FMs during the high tide was one order of magnitude higher than during the previous campaign, reaching a following peak of concentration of $16 \mu \mathrm{L} \mathrm{L}^{-1}$ during the mid-tide. The concentrations slightly decreased during low tide $\left(11 \mu \mathrm{g} \mathrm{L}^{-1}\right)$, likely due to lower emissions in the late afternoon if compared to the central part of the day. As expected, the tidal height plays an important role in determining the concentrations of FMs in the canals both in Venice and Burano. However, the importance of the local sources and their variability was highlighted once more.

Salicylates were observed to be the most abundant compounds also in the campaign S3 and the sum of Amyl, Hexyl and Benzyl Salicylate constituted $80 \%$ of the total FMs in sample Bu2S3B, confirming their importance as major consumed and emitted fragrances. Oranger Crystals, Ambrofix and Peonile were found in all the samples of S3, while Lemonile and Amberketal were in some cases at concentrations comparable to Salicylates. Unlike in campaigns S1 and S2, Ultravanil and 


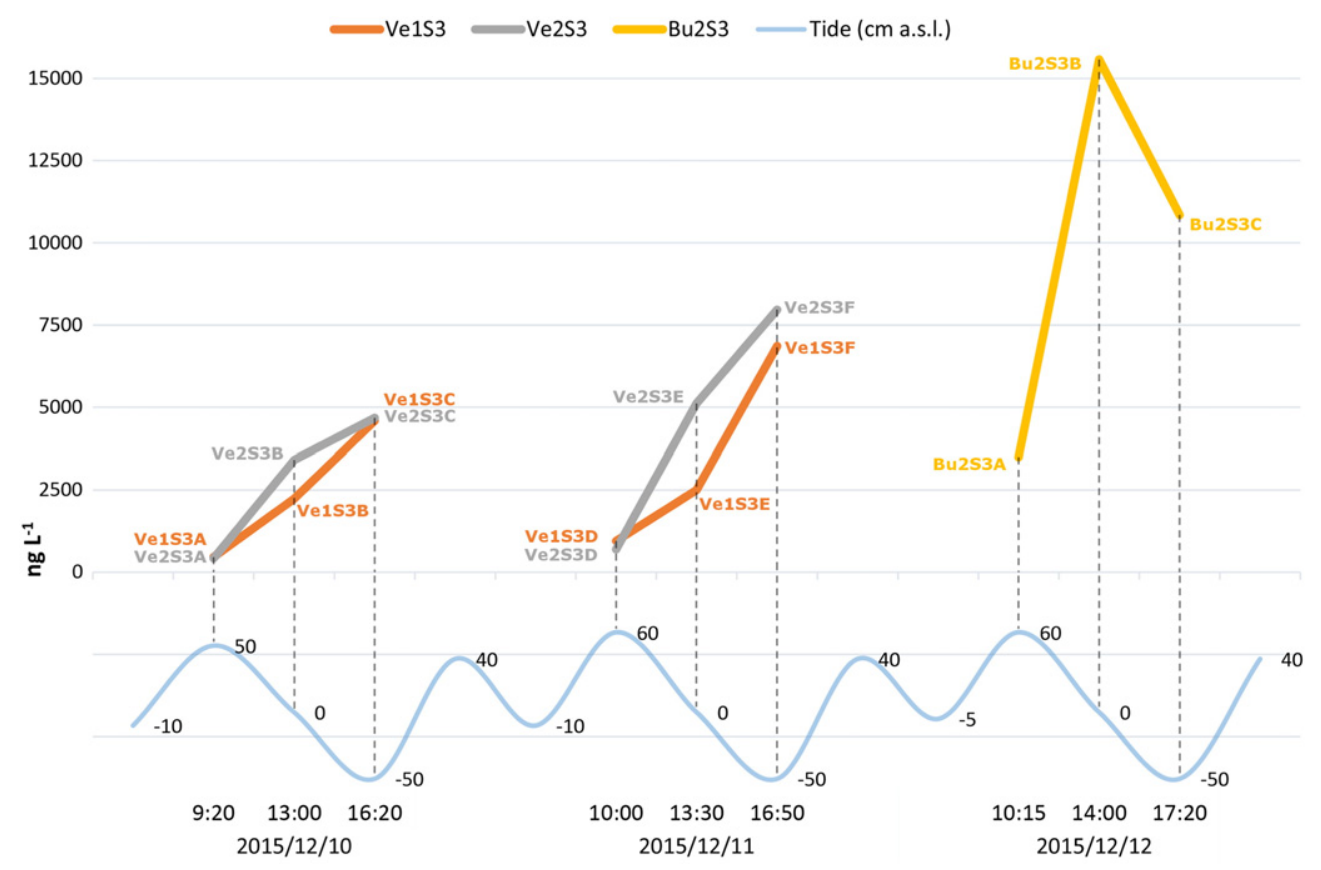

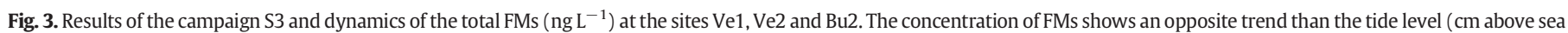
level, a.s.l.).

Pelargene were detected in a few samples, while Mefranal, Tridecene-2Nitrile and Dupical were again lower than detection limits.

\subsection{General considerations}

The results of the three campaigns evidenced how FMs are related to different dynamics in the various sites. The two most important factors are likely the presence and variability of emitting sources and the dilution effect. Once released in the water, also degradation of FMs and adsorption by particulate are processes that are likely to occur, however probably at a time scale slower than the tidal current. The most important consequence is that the water circulation due to tide excursion will likely transport the FMs emitted in the urban area throughout the lagoon. Italy is the most important consumer of detergents in Europe, with a consumption of $12.6 \mathrm{~kg}$ per capita per year vs. the EU average of $10.1 \mathrm{~kg}$ (HERA, 2004). The Italian law does not report emission limits for the $17 \mathrm{FMs}$. Considering the diary production of $250 \mathrm{~L}$ of untreated wastewater per person and an average percentage of $1 \%$ of FMs in the personal care and household products (Zhang et al., 2013) we can estimate with a large approximation a mean value of FMs in the sewage around $1 \mathrm{mg} \mathrm{L}^{-1}$. This value is consistent with those found in the samples (approximately in the range $0.1-10 \mu \mathrm{g} \mathrm{L}^{-1}$ ) considering that the 17 FMs are a fraction of the fragrances in the personal care and household products and taking into account the dilution effect of the water in the canals and the possible degradation phenomena. For instance, a primary treatment removes around 50\% of Benzyl Salicylate and other FMs from the wastewater (Simonich et al., 2000). This is almost the only process applied to sludge in Venice, although the coverage is only partial. For most of the samples, the concentrations reported above for benzyl and Hexyl Salicylate are comparable to or lower than the final effluent emitted from treatment plants (respectively $117 \pm 23$ and $15 \pm 4 \mathrm{ng} \mathrm{L}^{-1}$ ). The samples collected during the low tide are otherwise comparable the wastewater influent $\left(8960 \pm 5320\right.$ and $\left.4650 \pm 380 \mathrm{ng} \mathrm{L}^{-1}\right)$ (Simonich et al., 2000). Other studies report similar values for Benzyl Salicylate in WWTPs in Spain (Negreira et al., 2010) (Godayol et al., 2015) and Japan (Kameda et al., 2011). We can conclude that the inner canals of Venice and Burano become a sort of sewage, in particular in low tide conditions. Consequently, the concentrations of Benzyl Salicylate presented here (ldl-2400 $\mathrm{ng} \mathrm{L}^{-1}$ ) are the highest among those reported in the literature for surface waters: in Spain (nd-79 $\mathrm{ng} \mathrm{L}^{-1}$ ) (Negreira et al., 2010), (10-59 ng L ${ }^{-1}$ ) (Vila et al., 2016) and Japan (nd-197 ng L ${ }^{-1}$ ) (Kameda et al., 2011)

The maximum values of Salicylates found in our study $\left(2-7 \mu \mathrm{L} \mathrm{L}^{-1}\right.$ as single compound) are far below the acute ecotoxicity to Daphnia and other species (0.7-10 $\mathrm{mg} \mathrm{L}^{-1}$ ) reported by the RIFM (Belsito et al., 2012). However, even if these substances are not persistent pollutants in the strictest sense, they are persistently emitted in the environment, and we therefore cannot rule out chronic toxicity, also considering their oestrogenic effects or possible synergistic interactions (Charles and Darbre, 2009; Zhang et al., 2012). It is likely that the urban emissions containing FMs and other PCPs contribute to the overall toxicity of the waters and sediments at a level comparable to that of the industrial area (Picone et al., 2016), causing a decline of the plankton communities, if compared to other areas of the lagoon (Bianchi et al., 2003).

Consequently, the main open question is to identify the environmental fate of these substances, namely whether FMs degrade in the aqueous system, accumulate in sediments and biota or volatilize into the atmosphere. Future studies should focus in particular on those FMs detected more frequently and in higher concentrations, namely Salicylates, Oranger Crystals, Ambrofix and Peonile. Obviously, this potential concern regards not only the Venice lagoon but also any place where wastewater is not adequately managed.

\section{Acknowledgments}

This work was not financially supported by any dedicated funding and it was carried out with free available funds. The authors gratefully acknowledge Givaudan and the International Express Service (IES-Ingredients) for providing the commercial standards of FMs free of charge. We would like to thank Elga Lab water, High Wycombe UK, for supplying the pure water systems used in this study. We gratefully thank Dr. Daniela Almansi for her accurate revision of our manuscript.

\section{Appendix A. Supplementary data}

Supplementary data to this article can be found online at http://dx. doi.org/10.1016/j.scitotenv.2016.05.198. 


\section{References}

Argiriadis, E., Rada, E.C., Vecchiato, M. Zambon, S. Ionescu, G. Schiavon, M., Ragazzi, M. Gambaro, A., 2014. Assessing the influence of local sources on POPs in atmospheric depositions and sediments near Trento (Italy). Atmos. Environ. 98, 32-40. http:// dx.doi.org/10.1016/j.atmosenv.2014.08.035.

Belsito, D., Bickers, D., Bruze, M., Calow, P., Dagli, M.L., Dekant, W., Fryer, A.D., Greim, H Miyachi, Y., Saurat, J.H., Sipes, I.G., 2012. A toxicologic and dermatologic assessment of salicylates when used as fragrance ingredients. Food Chem. Toxicol. 50, 318-361. http://dx.doi.org/10.1016/j.fct.2012.04.019.

Bianchi, F., Acri, F., Aubry, F.B., Berton, A., Boldrin, A., Camatti, E., Cassin, D., Comaschi, A 2003. Can plankton communities be considered as bio-indicators of water quality in the lagoon of Venice ? Mar. Pollut. Bull. 46, 964-971. http://dx.doi.org/10.1016/ S0025-326X(03)00111-5.

Charles, A.K., Darbre, P.D., 2009. Oestrogenic activity of benzyl salicylate, benzyl benzoate and butylphenylmethylpropional (Lilial) in MCF7 human breast cancer cells in vitro. J. Appl. Toxicol. 29, 422-434. http://dx.doi.org/10.1002/jat.1429.

Daughton, C.G., Ternes, T.a., 1999. Pharmaceuticals and personal care products in the environment: agents of subtle change? Environ. Health Perspect. 107, 907-938. http:// dx.doi.org/10.1289/ehp.99107s6907.

Gambaro, A., Radaelli, M., Piazza, R., Stortini, A.M., Contini, D., Belosi, F., Zangrando, R., Cescon, P., 2009. Organic micropollutants in wet and dry depositions in the Venice lagoon. Chemosphere 76, 1017-1022. http://dx.doi.org/10.1016/j.chemosphere.2009. 04.063 .

Gaudin, J.M., 2014. The quest for odorants having salicylate notes. Flavour Fragr. J. 29, 77-86. http://dx.doi.org/10.1002/ffj.3182.

Godayol, A., Besalú, E., Anticó, E., Sanchez, J.M., 2015. Monitoring of sixteen fragrance allergens and two polycyclic musks in wastewater treatment plants by solid phase microextraction coupled to gas chromatography. Chemosphere 119, 363-370. http://dx.doi.org/10.1016/j.chemosphere.2014.06.072.

Gregoris, E. Argiriadis, E., Vecchiato, M., Zambon, S., De Pieri, S., Donateo, A. Contini, D. Piazza, R., Barbante, C., Gambaro, A., 2014. Gas-particle distributions, sources and health effects of polycyclic aromatic hydrocarbons (PAHs), polychlorinated biphenyls (PCBs) and polychlorinated naphthalenes (PCNs) in Venice aerosols. Sci. Total Environ. 476-477, 393-405. http://dx.doi.org/10.1016/j.scitotenv.2014.01.036.

Heisterberg, M.V., Menné, T., Johansen, J.D., 2011. Contact allergy to the 26 specific fragrance ingredients to be declared on cosmetic products in accordance with the EU cosmetics directive. Contact Dermatitis 65, 266-275. http://dx.doi.org/10.1111/j. 1600-0536.2011.01962.x

HERA, 2004. Environmental Risk Assessment Polycyclic Musks AHTN and HHCB.

Jonker, M.T.O., Koelmans, A.A., 2002. Sorption of polycyclic aromatic hydrocarbons and polychlorinated biphenyls to soot and soot-like materials in the aqueous environment: mechanistic considerations. Environ. Sci. Technol. 36, 3725-3734. http://dx. doi.org/10.1021/es020019x.

Kameda, Y., Kimura, K., Miyazaki, M., 2011. Occurrence and profiles of organic sunblocking agents in surface waters and sediments in Japanese rivers and lakes. Environ. Pollut. 159, 1570-1576. http://dx.doi.org/10.1016/j.envpol.2011.02.055.
Keil, R.G., Neibauer, J.A., 2009. Analysis of cooking spices in natural waters. Limnol. Oceanogr. 7, 848-855. http://dx.doi.org/10.4319/lom.2009.7.848.

Lamas, J.P., Sanchez-Prado, L., Garcia-Jares, C., Llompart, M., 2010. Determination of fragrance allergens in indoor air by active sampling followed by ultrasound-assisted solvent extraction and gas chromatography-mass spectrometry. J. Chromatogr. A 1217, 1882-1890. http://dx.doi.org/10.1016/j.chroma.2010.01.055.

Lapczynski, A., McGinty, D., Jones, L., Bhatia, S., Letizia, C.S., Api, A.M., 2007. Fragrance material review on benzyl salicylate. Food Chem. Toxicol. 45, S362-S380. http://dx.doi. org/10.1016/j.fct.2007.09.060.

Negreira, N., Rodríguez, I., Rubí, E., Cela, R., 2010. Dispersive liquid-liquid microextraction followed by gas chromatography-mass spectrometry for the rapid and sensitive determination of UV filters in environmental water samples. Anal. Bioanal. Chem. 398, 995-1004. http://dx.doi.org/10.1007/s00216-010-4009-9.

Peck, A.M., 2006. Analytical methods for the determination of persistent ingredients of personal care products in environmental matrices. Anal. Bioanal. Chem. 386, 907-939. http://dx.doi.org/10.1007/s00216-006-0728-3.

Picone, M., Bergamin, M., Losso, C., Delaney, E., Arizzi, A., Volpi, A., 2016. Ecotoxicology and environmental safety assessment of sediment toxicity in the lagoon of Venice ( Italy ) using a multi-species set of bioassays. Ecotoxicol. Environ. Saf. 123, 32-44. http://dx.doi.org/10.1016/j.ecoenv.2015.09.002.

Simonich, S.L., Begley, W.M., Debaere, G., Eckhoff, W.S., 2000. Trace analysis of fragrance materials in wastewater and treated wastewater. Environ. Sci. Technol. 34, 959-965. http://dx.doi.org/10.1021/es991018g.

Simonich, S.L., Federle, T.W., Eckhoff, W.S., Rottiers, A., Webb, S., Sabaliunas, D., De Wolf, W., 2002. Removal of fragrance materials during U.S. and European wastewater treatment. Environ. Sci. Technol. 36, 2839-2847. http://dx.doi.org/10.1021/es025503e.

Tashiro, Y., Kameda, Y., 2013. Concentration of organic sun-blocking agents in seawater of beaches and coral reefs of Okinawa Island, Japan. Mar. Pollut. Bull. 77, 333-340. http://dx.doi.org/10.1016/j.marpolbul.2013.09.013.

Vecchiato, M., Argiriadis, E., Zambon, S., Barbante, C., Toscano, G., Gambaro, A., Piazza, R., 2015. Persistent organic pollutants ( POPs ) in Antarctica: occurrence in continental and coastal surface snow. Microchem. J. 119, 75-82. http://dx.doi.org/10.1016/j. microc.2014.10.010.

Vila, M., Lamas, J.P., Garcia-Jares, C., Dagnac, T., Llompart, M., 2016. Ultrasound-assisted emulsification microextraction followed by gas chromatography-mass spectrometry and gas chromatography-tandem mass spectrometry for the analysis of UV filters in water. Microchem. J. 124, 530-539. http://dx.doi.org/10.1016/j.microc.2015.09.023.

Zhang, Z., Jia, C., Hu, Y., Sun, L., Jiao, J., Zhao, L., Zhu, D., Li, J., Tian, Y., Bai, H., Li, R., Hu, J., 2012. The estrogenic potential of salicylate esters and their possible risks in foods and cosmetics. Toxicol. Lett. 209, 146-153. http://dx.doi.org/10.1016/j.toxlet.2011. 12.004

Zhang, X., Brar, S.K., Yan, S., Tyagi, R.D., Surampalli, R.Y., 2013. Fate and transport of fragrance materials in principal environmental sinks. Chemosphere 93, 857-869. http://dx.doi.org/10.1016/j.chemosphere.2013.05.055. 